\title{
CEPHALOSPORINASE INTERACTIONS AND ANTIMICROBIAL ACTIVITY OF BMY-28142, CEFTAZIDIME AND CEFOTAXIME
}

\author{
Masaki Hiraoka, Shinj Masuyoshi ${ }^{\dagger}$ and Susumu Mitsuhashi \\ Episome Institute, \\ 2220 Kogure, Fujimi-mura, Seta-gun, Gunma 371-01, Japan
}

Kozo Tomatsu

Bristol-Myers Research Institute, 2-9-3 Shimomeguro, Meguro-ku, Tokyo 153, Japan

MATSUHisa INoue

\begin{abstract}
Laboratory of Drug Resistance in Bacteria, Gunma University, School of Medicine, 3-39-22 Shouwamachi, Maebashi 371, Japan
\end{abstract}

(Received for publication July 29, 1987)

\begin{abstract}
Cephalosporinases of Enterobacter cloacae and Citrobacter freundii were responsible for resistance to newer cephalosporins such as cefotaxime and ceftazidime but not BMY-28142. Interaction of these cephalosporins including hydrolysis, binding, inhibition, and inactivation with cephalosporinases from $E$. cloacae GN7471 and $C$. freundii GN7391 were studied. BMY-28142 was much more stable against the both enzymes than cephalothin, but more hydrolyzable than cefotaxime and ceftazidime at higher concentration such as $100 \mu \mathrm{M}$. Because of low affinity for the enzymes, i.e. large $K m$ and $K i$, the calculated hydrolysis rate of BMY-28142 at $0.1 \mu \mathrm{M}$ was smaller than those of cefotaxime and ceftazidime, that explained the difference in activity against cephalosporinase-producing strains between BMY-28142 and cefotaxime or ceftazidime. The effects of cephalosporinase production on susceptibility of Escherichia coli omp mutants were examined using a plasmid having cephalosporinase gene of $C$. freundii GN346. Decrease in susceptibility of $E$. coll by cephalosporinase production was larger in the strain lacking outer membrane proteins (Omp) F and C, and smaller in the strain producing $\mathrm{OmpF}$ constitutively.
\end{abstract}

BMY-28142, a new oxyiminocephalosporin, has excellent activity against both Gram-positive and Gram-negative bacteria ${ }^{1,2}$. Among these organisms, Enterobacter cloacae and Citrobacter freundii, which produce chromosomal cephalosporinases, are more susceptible to BMY-28142 than to other cephalosporins ${ }^{3 \sim 5)}$. Recently, the emergence of cephalosporinase hyperproducing strains in these species which show resistance to newer cephalosporins, such as cefotaxime and ceftazidime, was reported ${ }^{(6)}$. On the resistance mechanism of cephalosporinase-high-producing strains against the newer cephalosporins, the theory of a "non-hydrolytic barrier" has been proposed", ${ }^{7}$. BMY-28142 shows higher activity against these strains than other cephalosporins ${ }^{5)}$. The relation of its low affinity, i.e. large $K i$ values, for cephalosporinases and its high activity was reported in comparison with ceftazidime $^{\text {g) }}$. However, how the low affinity leads less influence of cephalosporinase production on activity is still unclear. On the other hand, the importance of very slow hydrolysis by cephalosporinases was also reported ${ }^{10)}$. In this paper, we attempted to clarify why BMY-28142 is so effective and examined kinetically the interaction of drugs with cephalosporinases using cephalothin, ceftazidime and

\footnotetext{
† Present address: Bristol-Myers Research Institute, 2-9-3 Shimomeguro, Meguro-ku, Tokyo 153, Japan.
} 
cefotaxime in comparison with BMY-28142.

\section{Materials and Methods}

\section{Antibiotics}

BMY-28142 was synthesized by Bristol-Myers Company in Syracuse, New York, and its sulfate salt $(830 \mu \mathrm{g} / \mathrm{mg})$ was used in this study. Other antibiotics were donated by Shin Nihon Jitsugyo Co., Ltd., for ceftazidime, Hoechst Japan Limited for cefotaxime, Merck-Banyu Co., Ltd., for cefoxitin, Shionogi \& Co., Ltd., for cephalothin.

\section{Bacteria and Plasmid}

Escherichia coli $\mathrm{MC4100}\left(\mathrm{F}^{-}\right.$SlacU169 araD139 rpsL relA thiA fibB) ${ }^{11)}$, E. coli $\mathrm{MH} 1160$ (MC4100 $o m p R 1)^{12)}$, and $E$. coli $\mathrm{MH} 760(\mathrm{MC} 4100 \mathrm{ompR2})^{13)}$ were kindly donated by S. Mizushima (Nagoya University, Nagoya, Japan). MH1160 lacks outer membrane proteins (Omp) F and C production. MH760 lacks OmpC production and produces OmpF constitutively, while in the parent strain,

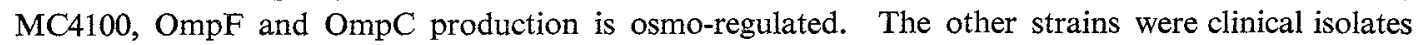
from several hospitals in Japan. Plasmid, pMS185, is a derivative of pACYC184 ${ }^{14)}$ carrying cephalosporinase gene from $C$. freundii GN346 (not published).

\section{Media}

Sensitivity Disk agar-N (SDN), i.e. modified Mueller-Hinton agar, sensitivity test broth, medium $\mathrm{B}^{15)}$, and nutrient agar with $1 \%$ sodium citrate ( $\left.\mathrm{pH} 6.8\right)$ were used.

\section{Susceptibility Test}

Antibiotic susceptibility was tested by a serial 2-fold agar dilution method in SDN. Approximately $10^{4} \mathrm{cfu}$ were inoculated onto agar plates. The MIC was defined as the lowest concentration preventing visual growth of bacteria after incubation for $18 \sim 20$ hours at $37^{\circ} \mathrm{C}$.

\section{Assay of Cephalosporinase}

Cephalosporinase was assayed by a spectrophotometric method ${ }^{16)}$, using a UV-265 spectrophotometer (Shimadzu). An absorbance change greater than 0.001 could be detected using this apparatus. Enzyme activity was determined at $30^{\circ} \mathrm{C}$ and $\mathrm{pH} 7.0$ in $50 \mathrm{~mm}$ phosphate buffer, using cephalothin $(100 \mu \mathrm{M})$ as substrate, and was expressed in terms of mol hydrolyzed per second (Kat). For the determination of cephalosporinase activity, a crude sonicate was used ${ }^{10)}$. Km and Vmax values were calculated from Lineweaver-Burk plots using least square method. To detect and determine hydrolysis rates of poor substrates, the concentration of cephalosporinases from $E$. cloacae GN7471 and C. freundii GN7391 used in the hydrolysis reaction mixture was $0.27 \mathrm{nKat} / \mathrm{ml}$ (E. cloacae) and $0.20 \mathrm{nKat} / \mathrm{ml}$ (C. freundii) for cephalothin and $803 \mathrm{nKat} / \mathrm{ml}($ E. cloacae $)$ and $160 \mathrm{nKat} / \mathrm{ml}(C$. freundii) for the other cephalosporins.

\section{Determination of Inhibition Constant}

$\overline{K i}$ values were calculated from initial hydrolysis rates of cephalothin $(10 \sim 100 \mu \mathrm{M})$ with and without a suitable concentration of inhibitor by Lineweaver-Burk plots using least square method. Pre-incubation of enzyme with inhibitor was not done to determine equilibrium constant of enzymeinhibitor (EI) complex formation, because hydrolysis and inactivation were observed in other experiments.

\section{Purification of Cephalosporinase}

The cephalosporinase of E. cloacae GN7471 and C. freundii GN7391 were prepared by sonication and CM-Sephadex ion-exchange chromatography as previously described ${ }^{15}, 17$. Further purification was not attempted, because the main active fraction of each enzyme after CM-Sephadex chromatography showed single band in SDS-PAGE, more than $95 \%$ purity, and high specificity $(8.0 \mu \mathrm{Kat} / \mathrm{mg}$ protein for $E$. cloacae, and $1.2 \mu \mathrm{Kat} / \mathrm{mg}$ protein for $C$. freundii) comparable to those of previous preparation ${ }^{15,17)}$. Protein was determined by the method of LowRY et al. ${ }^{18)}$, using bovine serum albumin as the standard. 


\section{Determination of Binding to the Cephalosporinase from E. cloacae GN7471}

The binding of cephalosporins to the cephalosporinase of E. cloacae GN7471 at $20 \mu \mathrm{M}$ of drug determined by a centrifugal ultrafiltration method ${ }^{19)}$ that has been used for determination of serum protein binding. One volume of drug solution (final $20 \mu \mathrm{M}$ ) in phosphate buffer ( $50 \mathrm{~mm}, \mathrm{pH} 7.0$ ) were mixed with same volume of various concentrations of the cephalosporinase solution (final $0.27 \sim$ $11 \mu \mathrm{Kat} / \mathrm{ml})$ in the buffer. An enzyme-free ultrafiltrate of the mixture was obtained by centrifugation at $3,000 \times g$ for 20 minutes using a Centricon 10 (Amicon). The drug concentration in the filtrate were determined by an agar-diffusion method using Bacillus subtilis ATCC 6633 as the test organism in nutrient agar containing $1 \%$ sodium citrate. For the control, the buffer was used instead of enzyme solution. Binding was expressed as binding ratio (B), i.e. the ratio of drug in the free state to total drug concentration, calculated from the following equation.

$\mathrm{B}(\%)=100 \times\left(\mathrm{C}_{0}-\mathrm{C}_{\mathrm{b}}\right) / \mathrm{C}_{0}$, where $\mathrm{B}$ was binding ratio, and $\mathrm{C}_{\mathrm{b}}$ and $\mathrm{C}_{0}$ were drug concentration in fittrate of the mixture with $\left(\mathrm{C}_{\mathrm{b}}\right)$ and without enzyme $\left(\mathrm{C}_{0}\right)$. Each preparation of ultrafiltrate was carried out within 30 minutes and below $4^{\circ} \mathrm{C}$ to minimize hydrolysis of drug, and was performed in duplicate. An enzyme concentration in which each agent showed half binding was obtained from binding-enzyme concentration curve.

Determination of Inactivation against the Cephalosporinase from C. freundii GN7391

The cephalosporinase from $C$. freundii $\mathrm{GN} 7391(97 \mathrm{nKat} / \mathrm{ml}$ : approx $2 \mu \mathrm{M}$, estimated by protein concentration and MW 38,000) was incubated at $30^{\circ} \mathrm{C}$ with $2 \mu \mathrm{M}$ of cephalosporin. Enzyme activity of the mixture was monitored during incubation using cephalothin as substrate, and was expressed in terms of percentage against activity of the mixture incubated without cephalosporin at same incubation time. No competitive inhibition would be expected in the enzyme activity assay, because the concentration of inhibitor in the assay reaction mixture was lowered below the level at which such inhibition would be detected, by 600 -fold dilution with substrate solution. The assay was performed in duplicate.

\section{Estimation of Hydrolysis Velocity}

Velocity of hydrolysis at $0.1 \mu \mathrm{M}$ of substrate was calculated from the following Michaelis-Menten equation.

$$
\mathrm{v}=\mathrm{V} \max /(1+K m /[\mathrm{S}])
$$

For cefotaxime, $K m$ values were assumed to be equal to $K i$ values. For the calculation of velocities at the cellular level, the amount and MW of the cephalosporinases from $E$. cloacae GN7471 and $C$. freundii GN7391 were taken to be $10^{5}$ molecules per cel1 ${ }^{6)}$, and 44,000 for E. cloacae ${ }^{152}$ and 38,000 for C. freundii ${ }^{17)}$.

\section{Results}

\section{Hydrolysis by Cephalosporinases from E. cloacae GN7471}

and C. freundii GN7391

To detect hydrolysis of BMY-28142, ceftazidime and cefotaxime, approximately 3,000 times (for the E. cloacae enzyme) or 1,000 times (for the C. freundii enzyme) more enzyme than that used in usual hydrolysis tests was used in this experiment. The initial hydrolysis velocities of BMY-28142, ceftazidime and cefotaxime at each series of initial substrate concentration by the enzyme from $E$. cloacae GN7471 is shown in Fig. 1. Hydrolysis rate-substrate concentration curves of the C. freundii enzyme were similar to those by the $E$. cloacae enzyme.

Hydrolysis velocity of BMY-28142 and ceftazidime by these enzymes decreased significantly as substrate concentration decreased. No such reduction was seen with cefotaxime for both enzymes. BMY-28142 was more hydrolyzable than cefotaxime and ceftazidime at $100 \mu \mathrm{M}$, which is the con- 
centration commonly used in hydrolysis test.

$K m$, Vmax and $K i$ values were shown in Table 1. The values were calculated from two or three experiments using one preparation of each enzyme. Vmax of BMY-28142 was about 6 times greater than that of ceftazidime for both enzymes, and was 15 times, for E. cloacae enzyme, or 120 times, for C. freundii enzyme, greater than that of cefotaxime.

Furthermore, the $K m$ value of BMY-28142 was about 15 times, for $E$. cloacae enzyme, or 30 times, for $C$. freundii enzyme, greater than that of ceftazidime. For cefotaxime, the exact $K m$ values could not be obtained, because those values were far smaller than the substrate concentrations used. During the complete hydrolysis of $10 \mu \mathrm{M}$ of cefotaxime by the enzyme from $E$. cloacae GN7471, the hydrolysis velocity was constant until the substrate was exhausted. The same observation was obtained from complete hydrolysis of $3 \mu \mathrm{M}$ of cefotaxime by the enzyme from C. freundii GN7391. Ki of BMY28142 was nearly one order of magnitude greater than that of ceftazidime and approximately four orders of magnitude greater than those of the other cephalosporins (Table 1).

Binding of Cephalosporins with the

Cephalosporinase from $E$. cloacae GN7471

At $20 \mu \mathrm{M}$ of drug concentration, BMY28142 showed much less binding ability with the cephalosporinase from E. cloacae GN7471 than ceftazidime or cefotaxime did. The enzyme concentration where the drugs showed $50 \%$ binding were $11 \mu \mathrm{Kat} / \mathrm{ml}$ for BMY-28142, 3.7 $\mu \mathrm{Kat} / \mathrm{ml}$ for ceftazidime and $1.1 \mu \mathrm{Kat} / \mathrm{ml}$ for cefotaxime. These results indicate that the cephalosporinase could decrease the concentration of cephalosporins in free state.

Reversible Inactivation with the

Cephalosporinase from C. freundii GN7391

When cefotaxime and ceftazidime were mixed with approximately equimolar $(2 \mu \mathrm{M})$ of the cephalosporinase from C. freundii GN7391, they showed inactivation of the enzyme, whereas
Fig. 1. Hydrolysis by the cephalosporinase from Enterobacter cloacae GN7471.

Enzyme concentration in the reaction mixture: $803 \mathrm{nKat} / \mathrm{ml}$. Substrates: BMY-28142 (O), ceftazidime $(\triangle)$ and cefotaxime $(\bullet)$.

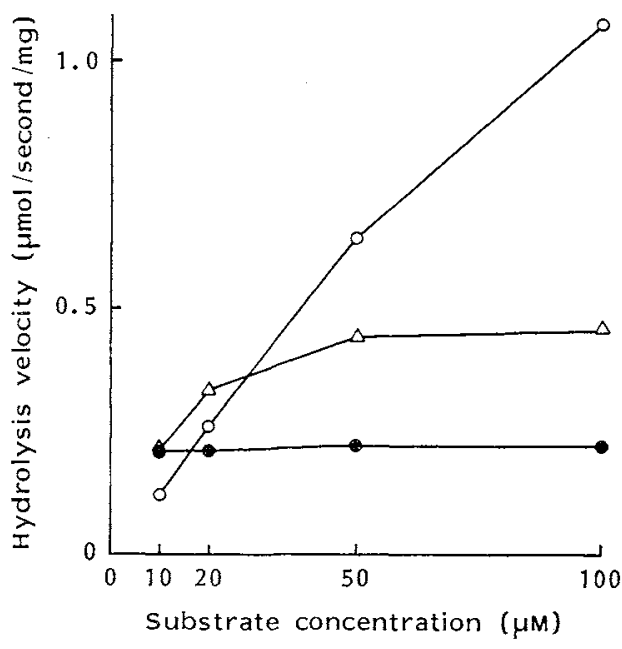

Table 1. Hydrolysis and inhibition kinetic parameters against cephalosporinases from Enterobacter cloacae GN7471 and Citrobacter freundii GN7391.

\begin{tabular}{|c|c|c|c|c|c|c|}
\hline \multirow[b]{2}{*}{ Antibiotic } & \multicolumn{3}{|c|}{ From E. cloacae GN7471 } & \multicolumn{3}{|c|}{ From C. freundii GN7391 } \\
\hline & $\begin{array}{c}V \max \\
\text { (nmol/second } \\
/ \text { mg protein) }\end{array}$ & $\begin{array}{c}K m \\
(\mu \mathrm{M})\end{array}$ & $\begin{array}{c}K i \\
(\mu \mathrm{M})\end{array}$ & $\begin{array}{c}\mathrm{Vmax} \\
\text { (nmol/second } \\
\text { /mg protein) }\end{array}$ & $\begin{array}{c}K m \\
(\mu \mathrm{M})\end{array}$ & $\begin{array}{c}K i \\
(\mu \mathrm{M})\end{array}$ \\
\hline Cephalothin & 9,300 & 76 & & 2,100 & 17 & \\
\hline BMY-28142 & 3.6 & 260 & $>200$ & 5.2 & 200 & $>200$ \\
\hline Ceftazidime & 0.57 & 17 & 31 & 0.85 & 6.8 & 37 \\
\hline Cefotaxime & 0.22 & - & 0.08 & 0.042 & - & 0.01 \\
\hline
\end{tabular}

-: $K m$ values could not be obtained for cefotaxime, because the values were far smaller than the substrate concentrations used. 
BMY-28142 did not (Fig. 2). Ceftazidime needed a few minutes of incubation to show maximum inactivation. This inactivation was reversible, and the enzyme activity of the mixture with cefotaxime or ceftazidime was recovered during incubation. Under the same conditions, none of these cephalosporins showed significant inactivation of the cephalosporinase from E. cloacae GN7471. These results indicate that the inhibition of cefotaxime and ceftazidime against cephalosporinases of $E$. cloacae and $C$. freundii was not the inactivation such as inactivation by suicide substrates.

\section{Estimation of Hydrolysis Velocity at Low Concentration}

The newer cephalosporins show very low MICs against susceptible strains, and their concentration preventing activity of the targets (penicillin binding proteins (PBPs)) in periplasmic space is supposed as $c a .0 .1 \mu \mathrm{M}^{10)}$. For comparison of hydrolysis rates of these cephalosporins at cellular level, the velocities at $0.1 \mu \mathrm{M}$ substrates were estimated from the Michaelis-Menten equation, using Vmax and $K m$ ( $K i$ for cefotaxime) values (Table 2 ). At $0.1 \mu \mathrm{M}$, the hydrolysis velocity of BMY-28142 was less than $0.07 \%$ of $V \max$, which was smaller than that of cefotaxime or ceftazidime, while those of cefotaxime and ceftazidime were $54 \sim 90 \%$ of Vmax and $0.6 \sim 1.5 \%$ of $V \max$, respectively.

Decrease of Antibacterial Activity against

E. coli omp Mutants by Production of Cephalosporinase of $C$. freundii

The effects of cephalosporinase production on the antibacterial activity of BMY-28142, ceftazidime, and cefotaxime against $E$. coli omp mutants was examined. The cephalosporinase activities of MC4100, MH1160, and MH760 carrying pMS185, which had cephalosporinase gene of C. freundii GN346, were $0.67 \sim 0.82$ $\mathrm{nKat} / \mathrm{mg}$ protein, whereas those of their host strains were not detected (less than $0.05 \mathrm{nKat} / \mathrm{mg}$

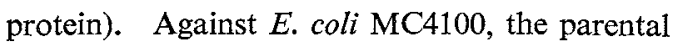
strain, the MIC of cefotaxime or ceftazidime was increased 4 to 8 -fold by cephalosporinase production, whereas the MIC of BMY-28142 was unchanged (Table 3). In the case against MH1160, which lacks OmpF and $\mathrm{C}$ production, the effects of cephalosporinase were more impressive with

Fig. 2. Reversible inactivation of the cephalosporinase from Citrobacter freundii GN7391.

Enzyme (approx $2 \mu \mathrm{M}, 97 \mathrm{nKat} / \mathrm{ml}$ ) was incubated at $30^{\circ} \mathrm{C}$ with $2 \mu \mathrm{M}$ of $\mathrm{BMY}-28142(\mathrm{O})$, ceftazidime $(\triangle)$, or cefotaxime $(\bullet)$.

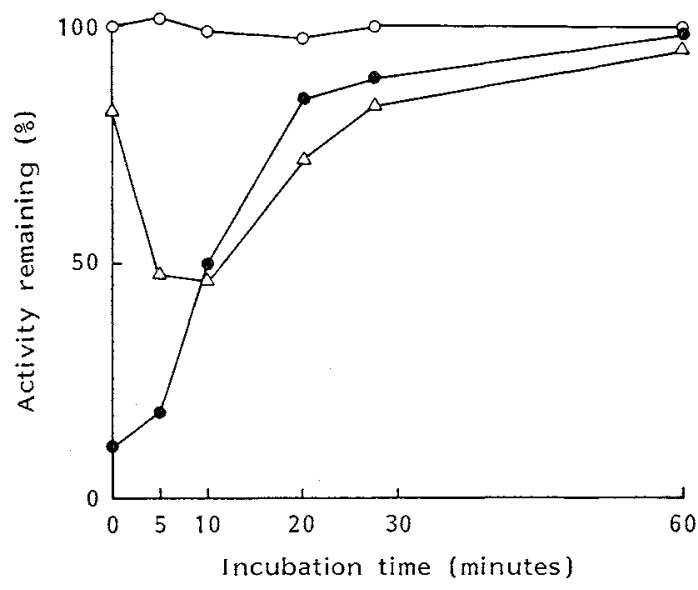

Enzyme activity of the mixture was monitored during the incubation, and was expressed in the terms of percentage against the activity of the mixture incubated without cephalosporins at same incubation time.

Table 2. Estimation of hydrolysis velocity at $0.1 \mu \mathrm{M}$ of substrate.

\begin{tabular}{cccccc}
\hline \multirow{2}{*}{ Antibiotic } & \multicolumn{2}{c}{ From Enterobacter } & cloacae GN7471 & & \multicolumn{2}{c}{ From Citrobacter freundii GN7391 } \\
\cline { 2 - 3 } & $\begin{array}{c}\text { nmol/second/ } \\
\text { mg protein }\end{array}$ & $\begin{array}{c}\text { Molecules/ } \\
\text { second/cell }\end{array}$ & & $\begin{array}{c}\text { nmol/second/ } \\
\text { mg protein }\end{array}$ & $\begin{array}{c}\text { Molecules/ } \\
\text { second/cell }\end{array}$ \\
\hline Cephalothin & 12 & 54,000 & & 12 & 45,000 \\
BMY-28142 & 0.0014 & 6.0 & & 0.0026 & 9.5 \\
Ceftazidime & 0.0034 & 15 & & 0.012 & 46 \\
Cefotaxime & 0.12 & 540 & & 0.038 & 140 \\
\hline
\end{tabular}


Table 3. Antibacterial activity against Escherichia coli omp mutants with or without carrying pMS185 which has cephalosporinase gene of Citrobacter freundii GN346.

\begin{tabular}{ccccc}
\hline \multirow{2}{*}{$\begin{array}{c}\text { Strain } \\
\text { (phenotype) }\end{array}$} & pMS185 & \multicolumn{3}{c}{ MIC $(\mu \mathrm{g} / \mathrm{ml})$} \\
\cline { 3 - 5 } & & BMY-28142 & Ceftazidime & Cefotaxime \\
\hline E. coli MC4100 (wild) & - & 0.025 & 0.05 & 0.025 \\
& + & 0.025 & 0.20 & 0.20 \\
& $+1-$ ratio & 1 & 4 & 8 \\
\hline E. coli MH1160 $\left(\mathrm{F}^{-}, \mathrm{C}^{-}\right)$ & - & 0.10 & 0.10 & 0.10 \\
& + & 0.39 & 1.56 & 1.56 \\
& $+1-$ ratio & 4 & 16 & 16 \\
\hline E. coli MH760 $\left(\mathrm{F}^{+}, \mathrm{C}^{-}\right)$ & - & 0.013 & 0.025 & 0.025 \\
& + & 0.013 & 0.10 & 0.05 \\
& $+1-$ ratio & 1 & 4 & 2 \\
\hline
\end{tabular}

a $\mathrm{F}^{-}$and $\mathrm{C}^{-}$mean lacking of $\mathrm{OmpF}$ and $\mathrm{OmpC}$, respectively. $\mathrm{F}^{+}$means constitutive production of OmpF.

$\mathrm{b}+$ and - are with and without carrying pMS185 which is a cloned plasmid having cephalosporinase gene of C. freundii GN346.

an increase in MIC was 16-fold for cefotaxime and ceftazidime and 4-fold for BMY-28142. Against MH760, which lacks OmpC and produces OmpF constitutively, the increase in MIC of cefotaxime

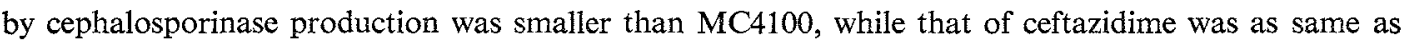
in MC4100. The MICs of BMY-28142 against MC4100 and MH760 were not affected by cephalosporinase production. These results indicate that omp mutation, which would decrease the outer membrane permeation rate of $\beta$-lactams, would increase the effects of cephalosporinase on antimicrobial activity of cephalosporins including BMY-28142.

\section{Discussion}

BMY-28142 showed much lower affinity for cephalosporinases (i.e. high $\mathrm{Km}$ and $\mathrm{Ki}$ ) than cefotaxime and ceftazidime. This observation agrees with the finding of PHELPs et al. ${ }^{97}$, that the excellent antibacterial activity of BMY-28142 originates in its low affinity for cephalosporinases. It is well known that some species of cephalosporinase-producing Gram-negative bacteria, such as $E$. cloacae, are less susceptible to cephalosporinase-stable $\beta$-lactams, e.g. cefotaxime, ceftazidime, etc. ${ }^{20,21}$. As to the mechanism of this resistance, there are controversial theories, in which affinity to cephalosporinase and very slow rate of hydrolysis are both considered ${ }^{9,21 \sim 23)}$.

Hydrolysis reaction of $\beta$-lactams by $\beta$-lactamases is expressed in the following equation ${ }^{20)}$.

$$
\mathrm{E}+\mathrm{S} \underset{k_{-1}}{\stackrel{k_{1}}{\longrightarrow}} \mathrm{ES} \stackrel{k_{2}}{\longrightarrow} \mathrm{M} \stackrel{k_{3}}{\longrightarrow} \mathrm{E}+\mathbf{P}
$$

where $\mathrm{E}$ is enzyme ( $\beta$-lactamase), $\mathrm{S}$ is substrate $(\beta$-lactam), $\mathrm{ES}$ is Michaelis complex, $\mathrm{M}$ is acyl intermediate, and $\mathbf{P}$ is product (inactivated $\beta$-lactam).

We determined the hydrolysis rates of cephalosporinase-stable cephalosporins (Table 1). Their Vmax values were significantly smaller than that of cephalothin. Among these cephalosporins, BMY28142 was most hydrolyzable at $100 \mu \mathrm{M}$. Therefore Vmax of hydrolysis alone cannot explain the activity of BMY-28142. However, the hydrolytic velocity of BMY-28142 decreased as the substrate concentration decreased, whereas that of cefotaxime did not (Fig. 1). To evaluate the role of hydrolysis velocity on the resistance to cephalosporins which are poor substrate, we estimated the rate of hydrolysis at low substrate concentration $(0.1 \mu \mathrm{M})$. Although cefotaxime and ceftazidime possess inhibitory activity against cephalosporinases, the inhibition was not irreversible inactivation (Fig. 2). Therefore it is reasonable to consider that Michaelis-Menten equation may be applicable to the hydrolysis reaction. Because the hydrolysis rate of cefotaxime did not decrease at the time when the 
substrate was almost exhausted, the $K m$ of cefotaxime was assumed to be equal to $K i$ in the estimation of hydrolysis rate of cefotaxime. From our estimation, the hydrolysis rate of BMY-28142 at $0.1 \mu \mathrm{M}$ was much lower than that of cefotaxime, and the difference in hydrolysis rate at $0.1 \mu \mathrm{M}$ well explained the difference in antimicrobial activity between BMY-28142 and cefotaxime. However, the rate of hydrolysis at $0.1 \mu \mathrm{M}$ could not explain the difference in activity between BMY-28142 and ceftazidime sufficiently, because the hydrolysis rate of ceftazidime at $0.1 \mu \mathrm{M}$ was only 3 or 5 times greater than that of BMY-28142.

On the other hand, we observed that presence of cephalosporinase decreased drug concentration in free state by binding. This binding might include both Michaelis complex (ES) and acyl intermediate (M) formation. Against the cephalosporinase from C. freundii, ceftazidime and cefotaxime showed reversible inactivation. This might be formation of acyl intermediate (M) which had rather long half-life. "Trapping" or "sponge effects" may be reduction of free drug concentration in periplasmic space by formation of $\mathrm{M}$ and/or ES complex which are the parts of hydrolysis reaction.

Because the hydrolysis rates of these cephalosporins was so slow, there needed consideration with permeation through outer membrane. Instead of direct comparison of hydrolysis rate with permeation rate, we determined the effects of cephalosporinase production on antimicrobial activity of the cephalosporins against $E$. coli omp mutants using a cloned plasmid carrying cephalosporinase gene of $C$. freundii. The permeation of cephalosporins through outer membrane has been considered to be simple diffusion through porin channels in outer membrane ${ }^{24)}$. E. coli MH1160 lacks OmpF and $\mathrm{C}$, so the permeation rate of cephalosporins in MH1160 may be lower than in E. coli MC4100 which is a parent of MH1160. Because of constitutive production of OmpF in MH760, the permeation

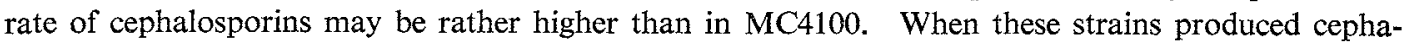
losporinase of $C$. freundii, susceptibility of these strains against cefotaxime, ceftazidime and BMY28142 decreased. The effects of the cephalosporinase was most significant in MH1160, in which permeation rate might be lower than in MC4100. Decrease in susceptibility of MH760 against ce-

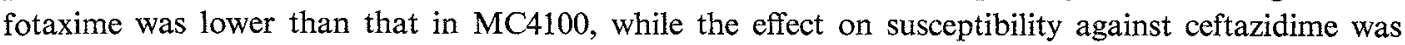
at same level in both MH760 and MC4100. Antimicrobial activity of BMY-28142 was affected by the cephalosporinase only against MH1160. These results indicate that ceftazidime had rather lower permeability than cefotaxime or BMY-28142, and also indicate that outer membrane permeability might lead synergic effects with hydrolysis by cephalosporinase on the resistance to these cephalosporins.

On the difference in antimicrobial activity between BMY-28142 and ceftazidime, there are two factors to be considered in addition to hydrolysis velocity. One is permeability through outer membrane discussed above. The other is affinity to PBPs. If ceftazidime needs rather higher concentration to inhibit PBPs than other cephalosporin does as discussed by VU and NiKAIDO ${ }^{10)}$, hydrolysis rate of ceftazidime may increase proportional to it concentration. Thus the difference in antimicrobial activity between BMY-28142 and ceftazidime may be explained by the synergic effects of the two factors and hydrolysis.

On the characteristics of $\beta$-lactams which activity is less affected by cephalosporinase production, there may be at least three types of agents. One is high stability against cephalosporinases at low concentration, that originates low affinity for the enzymes. BMY-28142 possesses this characteristics. Another is high stability caused by high affinity for the enzymes and acyl intermediate formation that have very long half life. Latamoxef may be this type ${ }^{25}$. The other is high permeability through outer membrane which would sufficiently reduce the effect of hydrolysis. Imipenem may be this type of agent ${ }^{24}$.

In conclusion, both "non-hydrolytic barrier", i.e., "trapping" or "sponge effects", and "very slow hydrolysis" are the theories in which hydrolysis reaction is watched from each side. Because of low affinity for cephalosporinases, BMY-28142 might be stable against the enzymes at low concentration still sufficient to inhibit the activity of PBPs. Therefore it showed excellent activity for cephalosporinase-producing bacteria.

\section{Acknowledgments}

We wish to thank R. E. KESSLER of Bristol-Myers Company for valuable discussion of this manuscript. 


\section{References}

1) Kessler, R. E.; M. Bies, R. E. Buck, D. R. Chisholm, T. A. Pursiano, Y. H. Tsai, M. Misiek, K. E. PrICE \& F. LeITNER: Comparison of a new cephalosporin, BMY 28142, with other broad-spectrum $\beta$-lactam antibiotics. Antimicrob. Agents Chemother. 27: $207 \sim 216,1985$

2) Khan, N. J.; J. A. Bihl, R. F. Scheld, J. L. LeFrock \& S. J. Weber: Antimicrobial activities of BMY28142, cefbuperazone, and cefpiramide compared with those of other cephalosporins. Antimicrob. Agents Chemother. 26: 585 590, 1984

3) Fuchs, P. C.; R. N. Jones, A. L. BARry \& C. Thornsberry: Evaluation of the in vitro activity of BMY28142, a new broad-spectrum cephalosporin. Antimicrob. Agents Chemother. $27: 679 \sim 682,1958$

4) Steele, J. C. H., Jr.; B. H. Edwards \& J. P. Rissing: In-vitro activity of BMY 28142, a new aminothiazolyl cephalosporin. J. Antimicrob. Chemother. 16:463 468, 1985

5) VuYE, A. \& J. PIJCK: In vitro antibacterial activity of BMY-28142, a new extended-spectrum cephalosporin. Antimicrob. Agents Chemother. 27: 574 577, 1985

6) SANDers, C. C. \& W. E. SANDers, Jr.: Microbial resistance to newer generation $\beta$-lactam antibiotics: clinical and laboratory implications. J. Infect. Dis. 151: 399 406, 1985

7) SANDERs, C. C.: Novel resistance selected by the new expanded-spectrum cephalosporins: a concern. J. Infect. Dis. 147: 585 589, 1983

8) Then, R. L. \& P. ANGeHrm: Trapping of nonhydrolyzable cephalosporins by cephalosporinases in Enterobacter cloacae and Pseudomonas aeruginosa as a possible resistance mechanism. Antimicrob. Agents Chemother. 21: $711 \sim 717,1982$

9) Phelps, D. J.; D. D. Carlton, C. A. Farrell \& R. E. Kessler: Affinity of cephalosporins for $\beta$-lactamases as a factor in antibacterial efficacy. Antimicrob. Agents Chemother. 29: 845 848, 1986

10) VU, H. \& H. NIKAIDO: Role of $\beta$-lactam hydrolysis in the mechanism of resistance of a $\beta$-lactamaseconstitutive Enterobacter cloacae strain to expanded-spectrum $\beta$-lactams. Antimicrob. Agents Chemother. 27: $393 \sim 398,1985$

11) Casadaban, M. J.: Transposition and fusion of lac genes to selected promoters in Escherichia coli using bacteriophage lambda and Mu. J. Mol. Biol. 104: 541 555, 1976

12) Hall, M. H. \& T.J. Silhavy: Genetic analysis of the ompB locus in Escherichia coli K-12. J. Mol. Biol. 151: $1 \sim 5,1981$

13) Hall, M. H. \& T. J. SILHAvY: The $o m p B$ locus and regulation of the major outer membrane proteins of Escherichia coli K-12. J. Mol. Biol. 146: 23 43, 1981

14) Chang, A. C. Y. \& S. N. CoHEN: Construction and characterization of amplifiable multicopy DNA cloning vehicles derived from the P15A cryptic miniplasmid. J. Bacteriol. 134: 1141 1156, 1978

15) Minami, S.; M. Inoue \& S. Mitsuhashi: Purification and properties of cephalosporinase from Enterobacter cloacae. Antimicrob. Agents Chemother. 18: 853 857, 1980

16) Minami, S.; A. Yotsuin, M. Inoue \& S. Mrtsuhashi: Induction of $\beta$-lactamase by various $\beta$-lactam antibiotics in Enterobacter cloacae. Antimicrob. Agents Chemother. 18:382 385, 1980

17) Ta.ma, M.; Y. Takenouchr, S. Sugawara, M. Inoue \& S. Mrtsuhashi: Purification and properties of chromosomally mediated $\beta$-lactamase from Citrobacter freundii GN7391. J. Gen. Microbiol. 121: 449 456,1980

18) Lowry, O. H.; N. J. Rosebrough, A. L. FARR \& R. J. RAndall: Protein measurement with the Folin phenol reagent. J. Biol. Chem. 193: 265 275, 1951

19) Murakawa, T.; Y. WAKaI, Y. Tor \& M. Nishida: Studies on binding of penicillins and serum protein. Jpn. J. Antibiotics 22: $387 \sim 393,1969$

20) Bush, K. \& R. B. SyKes: Interaction of $\beta$-lactam antibiotics with $\beta$-lactamases as a cause for resistance. In Antimicrobial Drug Resistance. Ed., L. E. BRyAN, pp. $1 \sim 31$, Academic Press Inc., New York, 1984

21) Seeberg, A. H.; R. M. Tolxdorff-Neutzling \& B. Wiedemann: Chromosomal $\beta$-lactamases of Enterobacter cloacae are responsible for resistance to third-generation cephalosporins. Antimicrob. Agents Chemother. 23: 918 925, 1983

22) Livermore, D. M.: Do $\beta$-lactamases 'trap' cephalosporins? J. Antimicrob. Chemother. 15: $511 \sim 514,1985$

23) PIDDock, L. J. V. \& R. WISE: Newer mechanisms of resistance to $\beta$-lactam antibiotics in Gram-negative bacteria. J. Antimicrob. Chemother. 16: $279 \sim 284,1985$

24) Yoshimura, F. \& H. Nrkaido: Diffusion of $\beta$-lactam antibiotics through the porin channels of Escherichia coli K-12. Antimicrob. Agents Chemother. 27: 84 92, 1985

25) Murakami, K. \& T. Yoshida: Covalent binding of moxalactam to cephalosporinase of Citrobacter freundii. Antimicrob. Agents Chemother. 27: $727 \sim 732,1985$ 